\title{
Moricizine Hydrochloride
}

National Cancer Institute

\section{Source}

National Cancer Institute. Moricizine Hydrochloride. NCI Thesaurus. Code C47626.

The hydrochloride salt form of moricizine, a phenothiazine analog with class I

antiarrhythmic activity. Moricizine hydrochloride blocks the rapid flow of sodium ions into the myocardial cell during phase 0 of the action potential. This decreases excitability, slows the impulse conduction through the atrioventricular (AV) node and depresses depolarization. 